\title{
Educar es gobernar. Orígenes, fulgor y fines del triestamentalismo
}

\author{
Miguel Ernesto Orellana Benado
}

Orjikh Editores, Santiago, Chile, 2016, 142 p.

\author{
Sergio Peña Neira \\ Universidad Mayor, Santiago, Chile. \\ Email: sergio.penaneira@gmail.com
}

Esta es una síntesis interesante de un debate desarrollado en Chile entre 2003 y 2017, pero que tiene raíces más antiguas.El debate se centra en la educación, el rol del Estado en ella y, particularmente, el gobierno de las universidades estatales. Su autor es un observador crítico del "triestamentalismo" y de la Universidad como institución, un conjunto de temas digno de análisis. Un ejemplo es la tesis que ni la docencia ni la investigación deben ser evaluadas con criterio político-partidista. La adscripción a un partido político del investigadorno debe reemplazar como fundamento de la valoración a los méritos intrínsecos de las distintas propuestas.

Orellana Benado, profesore investigador asociado en la Facultad de Derecho de la Universidad de Chile, es doctor en filosofía de la Universidad de Oxford donde fueJunior CommonRoomScholar(distinción que incluía financiar sus estudios de postgrado) delBalliolCollege, el más antiguo en esa universidad, la más antigua de habla inglesa. Esto explica su amplio conocimiento de esa institución.

Los estudiantes, ha dicho Orellana Benado, "son como el aire, entran y salen del cuerpo de la universidad”, frase, en parte, basada en sus años de estudio, como contraste a lo propuesto en Chile, inspiran al lector en búsqueda de excelencia académica y estudiantil. Asimismo, expone las violentas diferencias entreOxford y algunas universidades chilenas de "eli-

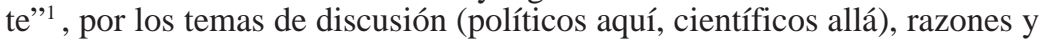
fundamentos de discusiones, investigación universitaria y posesión de "autoridad" conforme a fuentes normativas establecidas. Ciertamente, mi propia experiencia en universidades inglesas, me reveló el rigor de análisis y comprensión por parte de los estudiantes de la seriedad de la tarea universitaria que lideran los profesores. La exigencia académica no es sino parte del inventario del éxito de esta universidad.

En el inicio declara al "triestamentalismo" un "leviatán de intimidante rostro y de credo jacobino cuya "lucha final” está a punto de imponer 
una tesis inédita y de mortíferas repercusiones” (p. 23). Ciertamente, es más que una opinión, dado que la fundamenta, es un argumento. Esto fija el objeto de discusión: el "triestamentalismo" y sus consecuencias (la promoción de huelgas y ocupaciones de las universidades). Orellana Benado apunta al apoyo que éste recibe de una combinación de "medidas de fuerza bajo un astuto camuflaje discursivo y de la simpatía soterrada de autoridades tanto políticas como educacionales” (p. 23). Donde quizás mejor muestra su genio sea en el análisis de la tesis básica de este movimiento:

\begin{abstract}
“(...) la universidad consistiría en la unión de tres estamentos (funcionario, estudiantil y académico), motivo por que la fuente última de autoridad-es decir, del poder con legitimidad y al que corresponde contar con medios para orientar, normas, evaluar, adjudicar, premiar y sancionar-al interior de la institución encargada de custodiar el saber y el conocimiento, de formar sobre esa base profesionales y académicos así como (cuando todo sale bien) de incrementar nuestro entendimiento y nuestro control sobre el mundo en que vivimos, son las decisiones de una “comunidad democrática”.
\end{abstract}

No queda claro sila “comunidad democrática” que promueve el triestamentalismo, lo sería en términos formales o bien sustanciales, cómo diferenciarla de una mera horda. Al menos, una consecuencia, en mi opinión, es la horda. Horda que no entiende lo que reclama, donde "democracia” es comprendida de mil formas y, obviamente, “acomodada” al grupo o a la persona que la usa pensando, sin duda, en un sentido publicitario, mitológico, legendario. La “democracia” no existirá jamás para quienes la entiendan como libertinaje o libertad carente de responsabilidad o los que no entiendan la necesidad de contar con definiciones acerca del actuar, en este caso, universitario.

Analiza el autor el serio y grave problema de las “tomas” y paros, la destrucción de equipos e instalaciones de las universidades, así como el daño que causan al aprendizaje en la educación (p. 23), explicando su sentido y alcance (p. 24), así como, sus causas y su heterogeneidad (p. 25). Donde acentúa su crítica es la posibilidad de discutirse la realidad social de un grupo de personas en el Parlamento por medio de una ley sin ofrecer razones de dicha propuesta (p. 25) en contraposición a otros temas de igual o mayor relevancia. Olvida el autor que el poder no necesita razones para actuar. Origen de lo planteado sería, según el autor, la decadencia económica del siglo XIX (los beneficios perdidos del salitre) y que, por su extensión temporal, en conjunto con la Guerra Fría, serían las causas últimasdel golpe de Estado de 1973 y, finalmente, del triestamentalismo.

El triestamentalismo es deconstruido: los motivos de sus propuestas (limitar el acceso de estudiantes universitarios de universidades privadas a la gratuidad), la ausencia de pensamiento crítico, los problemas de ego por popularidad ante las masas y definición de lo que se debe investigar.La co-determinación de qué investigar (y agregamos, cómo) haría sangrar hasta fallecer a las comunidades investigativas chilenas (p. 27). 
“El mando en la tarea formativa corresponde a los que saben” (p. 27) esta frase resultaría una perogrullada o "truismo" (en palabras de J. Raz), sien Chile no fueren los fundamentos de esta afirmación atacados con un grado de estulticia e ignorancia supina. Quienes atacan el poder o autoridad en la formación, rompen con ésta. En este contexto, la relación entre académicos y universitarios (miembros iniciales, intermedios o consagrados de la comunidad científico investigativa de la universidad) es fundamental.

Efectivamente,la instalación de un cogobierno triestamental paritario (sistema en que los tres "estamentos” tienen el mismo poder) haría desaparecer, es mi opinión, casi de inmediato, a la comunidad científica nacional (con una investigación extraordinariamente pequeña relacionado casi todo con la mirada de una ínsula al mundo). Si hoy es mejor publicar en el extranjero es imaginable la consecuencia de una evaluación de publicaciones reducida a simpatía y liviandad de mayorías y minorías donde frases hechas, mitos, leyendas campean entre los que o no entienden, pero añoran ser investigadores o no entienden y desprecian a los investigadores o los que no entienden y rechazan la investigación porque miran todo con “afán profesionalizante” (como señaló una vez un distinguido penalista español).

Asimismo, OrellanaBenado enfrenta con realismo la “teoría” del triestamentalismo que sería una “innovación” única desde la creación de la institución universitaria misma (p. 33). Sería una suerte de revolución más, de las múltiples que ha tenido Chile. Su análisis de las décadas de 1960 y 1970 indica las “revoluciones” de centro, izquierda y derecha de tales años. Vivir en revoluciones y no evoluciones es vivir con fiebre constante y ataques al corazón permanentes. Su análisis de la realidad social chilena desde 1980 (inclusive anterior) es brillante. Por ejemplo, la especulación acerca de que,durante la crisis económica de 1982, para sobrevivir, el pueblo chileno comió perros vagos (lo que resulta de gran crudeza), lo que explicaría la actual sobrepoblación canina en las principales ciudades.

El “cuidar la educación desde la raíz hasta la flor” es, sin duda, fundamental en forma y fondo el elemento principal o leitmotiv del libro. Esto en razón, según el autor, de preservar la educación para convertirnos en un país desarrollado, cuestión no alcanzada, por despilfarro de los beneficios o lucro obtenido de los recursos naturales no renovables durante, al menos, dos periodos de nuestra vida republicana (p. 39). El conferir grados académicos en una comunidad de profesores y alumnos constituye el elemento central de lo que es la universidad en la primera de sus acepciones (p. 42). Las razones, sin embargo, para la existencia del triestamentalismo y ausencia de participación académica en la universidad se debería, según Orellana Benado, al desinterés de los académicos en las tareas administrativas (a fin de dedicarse al leitmotiv de la universidad: educación, investigación, extensión) y de los alumnos más aventajados en discutir al triestamentalismo (acuciados de estudiar y terminar sus estudios a fin de ingresar, según mi observación, en el mundo del trabajo) (p. 44). 
El crimen de disminuir la educación en su sentido sustantivo, de amplia repercusión, se habría cometido durante el gobierno militar, la dictadura (pp. 45-46). Lamentablemente, discrepamos de dicha visión, la educación básica, media y universitaria ha sido objeto de destrucción o negligencia grave producto de las diversas políticas y leyes que han incorporado nuevas personas a la educación superior sin requisitos o exigencias mínimas. Se agrega a lo anterior el "argumento" de la democracia, si es democrático (conforme a los parámetros del triestamentalismo), es suficiente. No hay un concepto de democracia, ni formal ni substantiva que no diga relación con ausencia de frenos de todo tipo: “democrático" es lo que no tiene límites.

Así, continuando con el triestamentalismo, el "trabajo universitario" debe servir a "las necesidades del pueblo" (p. 46). En eso Orellana Benado muestra su oposición y desacuerdo. Si miramos con cuidado, sin embargo, las investigaciones están en favor de las necesidades del "pueblo" (la más básica, conocer, aprender, dar trabajo, generar trabajos), salvo que se extienda el concepto de "ciencia básica", onerosa enlas ciencias en general y Ciencia Jurídica en particular porque, no es ir a tribunales, elaborar contratos, sino preguntarnos problemas básicos ("lagunas jurídicas”, noción de justicia en el Derecho, definición de razonamiento jurídico, determinación del Estado de Derecho internacional, laguna de derecho internacional sobre las microfibras de plástico, efectos jurídicos del cambio climático o regulación de la división equitativa y justa de los beneficios obtenidos de un objeto jurídico).

El texto merece ser leído por sus aportes, por cierto, muchos de ellos, contrarios al triestamentalismo. Sin embargo, Orellana Benado nos adentra en la belleza y dificultad del mundo académico, así como sus caminos de excelencia. Es, a veces, de gran profundidad e interés y, otras veces, de un grado de violencia abisal por la realidad que describe. A cualquiera, interesado en la universidad, en los problemas actuales y en la realidad de Chile, debe leer este libro riguroso y sencillo y lo que es más interesante, diferente por la variedad de temas que analiza bajo el foco del desarrollo de la universidad y, dentro de la misma, de la investigación. No crítica la presencia de la política partidista en la universidad, pero la coloca en su lugar y en su momento. En mi opinión, hoy más que nunca es necesario debatir lo que debe ser la universidad como institución y cómo irradiar su conocimiento. 


\section{Nota}

${ }^{1}$ Orellana Benado indica que las fuentes normativas de "elite" pueden ser conocimiento, riqueza material, posición institucional política, imagen ante la opinión pública gracias a su desempeño en medios de comunicación. Claramente nos encontramos en la primera fuente. 